SOME biological parameters before and after an acute episode of cigarette smoking in rats have been evaluated. The carboxyhaemoglobin levels depended either on the number of cigarettes, or on the time of exposure to cigarette smoke and returned to pre-smoking values in about $2 \mathrm{~h}$. The evaluation of the kinetics of alveolar and peritoneal macrophages in rats after a smoking session of three cigarettes within an hour, indicated that alveolar macrophages in the bronchoalveolar lavage fluid significantly increased $8 \mathrm{~h}$ after the smoking, whereas the number of peritoneal macrophages remained practically constant. The incubation of these cells for various times at $37^{\circ} \mathrm{C}$ in a humidified atmosphere, resulted in a spontaneous release, $24 \mathrm{~h}$ thereafter, of variable amounts of tumour necrosis factor $\alpha$ (TNF $\alpha$ ), which remained practically constant during the following days. Neither alveolar macrophages of control rats, nor peritoneal macrophages of both control and smoking rats were able to release TNF $\alpha$. Moreover, after lipopolysaccharide induction of alveolar macrophages of both control and smoking rats, an increased release of $\mathrm{TNF} \alpha$ was observed, indicating that these cells were in an active state.

Key words: Alveolar macrophages, Cigarette smoke, LPS induction, $\mathrm{TNF} \alpha$

\section{Effects of acute cigarette smoke exposure on macrophage kinetics and release of tumour necrosis factor $\alpha$ in rats}

\author{
G. P. Pessina, ${ }^{1}$ L. Paulesu, ${ }^{1}$ \\ F Corradeschi, ${ }^{1}$ E. Luzzi, ${ }^{1}$ A. Di Stefano, ${ }^{2}$ \\ M Tanzini, ${ }^{1}$ G. Matteucci ${ }^{3}$ and V. Bocci,cA \\ ${ }^{1}$ Institute of General Physiology, University of \\ Siena, via Laterina 8, 53100 Siena, Italy; \\ ${ }^{2}$ Department of Molecular Biology, University of \\ Siena, 53100 Siena, Italy; ${ }^{3}$ Biocine-Sclavo S.p.A., \\ via Fiorentina, $\mathbf{5 3 1 0 0}$ Siena, Italy \\ ${ }^{\mathrm{CA}}$ Corresponding Author
}

\section{Introduction}

Cigarette smoking is a useful human model of chronic inflammation ${ }^{1}$ and it is well known that inflammation may contribute to the destruction and remodelling of normal lung architecture. Cigarette smoking, exposing the surface of the lower respiratory tract to more than 4000 chemical constituents, ${ }^{2}$ has been associated with an inflammatory process. $^{3}$ Moreover, inflammation leads to an emigration, either of monocytes or polymorphonuclear cells, from the vasculature to the tissue. Alveolar macrophages, which are derived from blood monocytes, exert their inflammatory activities at the various sites either directly, or through the action of tumour necrosis factor (TNF) and other immunological mediators. ${ }^{4}$ TNF $\alpha$ is chemotactic for monocytes and polymorphonucleate cells (PMN), stimulates phagocytosis, causes adherence to endothelium and production of oxygen-derived metabolites, induces procoagulant activities in cultured human endothelial cells, and activates macrophages resulting in interleukin- 1 and prostaglandin E2 production. ${ }^{4-6}$ Thus the locally regulated generation of $T N F \alpha$ at sites of injury represents an important autocrine-paracrine control mechanism which operates in acute inflammatory response. $^{4}$

Evaluation of the acute effect of cigarette smoking in human non-smokers is uncertain because they do not inhale cigarette smoke deeply. ${ }^{7}$
For this reason research has been carried out to study either the acute effect of cigarette smoking in human smokers, ${ }^{7}$ or in small animals, ${ }^{8}$ or the effect of cigarette smoke in blood cells in vitro., ${ }^{9,10}$ Assuming that the activation of macrophages is an important event for the pleiotropic effects of these cells, the present study was undertaken to investigate some biological parameters after acute tobacco smoking and the ability of cigarette smoke to activate rat alveolar macrophages, thus causing the release of TNF $\alpha$. We also examined whether the release of TNF $\alpha$ by alveolar macrophages of rats exposed to an episode of acute, passive cigarette smoking, would be influenced by the presence of lipopolysaccharide (LPS).

\section{Materials and Methods}

Animals: Outbred Wistar male rats (Charles River) of about $280 \mathrm{~g}$ body weight were used throughout the experiments. Groups of six rats were each lodged in the smoke chamber for various periods of time as indicated in Table 1. Smoke was generated in the smoke apparatus using a varied number of cigarettes without filter (Camel). This particular brand was chosen only because it is an internationally known brand of cigarettes. Immediately after smoking $(0 \mathrm{~h})$ and after 2, 4, 8 and $24 \mathrm{~h}$, animals were sacrificed by an overdose of nembutal (Serva, Heidelberg). Blood was withdrawn from the femoral vein with an insulin type syringe containing 
Table 1. Correlation between number of cigarettes, smoking period and $\mathrm{COHb}$ blood levels in rats measured immediately after the smoking session

\begin{tabular}{cccr}
\hline Smoking $(\mathrm{h})$ & Cigarettes $(n)$ & Rats $(n)$ & COHb (\%) \\
\hline 2 & 1 & 6 & $17.1 \pm 2.2$ \\
1 & 3 & 8 & $16.4 \pm 3.6$ \\
1 & 1 & 6 & $9 \pm 2.5$ \\
0 & 0 & 4 & $-1 \pm 1.1$ \\
\hline
\end{tabular}

$10 \mathrm{IU} / \mathrm{ml}$ of heparin (Liquemin, Roche), for the measurement of carboxyhaemoglobin (COHb), by reading the absorbance at $276.5 \mathrm{~nm}$ in a spectrophotometer (Spectra Comp.601, Carlo Erba). Afterwards, $10 \mathrm{ml}$ of sterile Hanks' balanced solution, $\mathrm{pH} 7.4$, containing $5 \mathrm{IU} / \mathrm{ml}$ heparin was injected into the peritoneal cavity, the abdomen was gently massaged and then about $7 \pm 1 \mathrm{ml}$ of peritoneal fluid $(\mathrm{PF})$ was aspirated for the collection of peritoneal macrophages.

Bronchoalveolar lavage was performed in the rats through a catheter inserted into the trachea with heparinized $(10 \mathrm{IU} / \mathrm{ml})$ sterile Hanks' solution. Five washes of $10 \mathrm{ml}$ each were carried out in rapid succession and the lavage fluids were pooled. Recovery was about $90 \%$. Lavage fluid was then centrifuged at $300 \times \mathrm{g}$ for $10 \mathrm{~min}$ at $4^{\circ} \mathrm{C}$ and the sedimented cells shown to be macrophages (more than 95\%) by nonspecific esterase staining. Separated macrophages were tested for viability by the Trypan blue exclusion method and more than $95 \%$ of cells were found to be viable. The number of macrophages was evaluated by at least three countings in a Bürker chamber.

Control animals (air-sham exposed rats) were subjected to the same procedure except that the chamber was insufflated with air only.

Cell culture: For the experiments evaluating the eventual production of TNF $\alpha$, cells from BAL and $\mathrm{PF}$, collected immediately after $(0 \mathrm{~h})$ and 4,8 and $24 \mathrm{~h}$ after the smoking session of three cigarettes for $1 \mathrm{~h}$, were diluted to the desired final concentration $\left(10^{6}\right.$ cells $\left./ \mathrm{ml}\right)$ with RPMI 1640 containing $10 \%$ heat-inactivated foetal calf serum (FCS), $2 \mathrm{mM}$ glutamine, $100 \mathrm{U} / \mathrm{ml}$ penicillin $\mathrm{G}$ and $100 \mu \mathrm{g} / \mathrm{ml}$ streptomycin. One hundred microlitres of the cell suspensions (about $10^{5}$ cells) were added to each well in 96-well culture plates (Costar) and were incubated for 24,48 and $72 \mathrm{~h}$ at $37^{\circ} \mathrm{C}$ in a humidified atmosphere ( $95 \%$ air $\left./ 5 \% \mathrm{CO}_{2}\right)$. A second batch of cells, collected 0,8 and $24 \mathrm{~h}$ after the smoking session and layered as above, was challenged with $1 \mu \mathrm{g} / \mathrm{ml}$ bacterial lipopolysaccharide (LPS) from Escherichia coli (Sigma) and incubated for $24 \mathrm{~h}$ at $37^{\circ} \mathrm{C}$. Then the plates were centrifuged and supernatants were stored at $-80^{\circ} \mathrm{C}$ until TNF $\alpha$ was determined.
Sediments, after two washings with normal saline, were dissolved in $0.1 \mathrm{~N} \mathrm{NaOH}(0.1 \mathrm{ml}$ per well, $12 \mathrm{~h}$ at room temperature) and proteins were measured by the method of Lowry et al. ${ }^{11}$ with some modifications.

TNF $\alpha$ determination: TNF activity was determined by the method of Ruff and Gifford ${ }^{12}$ with some modifications. Briefly, L929 cells were seeded at a density of $4 \times 10^{4}$ cells per well in 96-well culture dishes in $100 \mu \mathrm{l}$ of Eagle's MEM supplemented with $10 \% \mathrm{FCS}$ and antibiotics. After $4 \mathrm{~h}$ incubation at $37^{\circ} \mathrm{C}$ in a humidified atmosphere $(95 \%$ air $\left./ 5 \% \mathrm{CO}_{2}\right)$, two-fold serial dilutions of the samples in $2 \mu \mathrm{g} / \mathrm{ml}$ of actinomycin D (Serva), were prepared in separate 96 -well culture dishes. Then $100 \mu \mathrm{l}$ of each dilution was transferred into the corresponding well and the plates were further incubated for $18 \mathrm{~h}$ at $37^{\circ} \mathrm{C}$ in the humidified atmosphere. Supernatants were then removed and cells stained with $0.1 \%$ crystal violet. After drying, $100 \mu \mathrm{l}$ of $33 \%$ acetic acid was added to each well to dissolve the dye. Plates were finally read at $540 \mathrm{~nm}$ on a Titertek Multiskan microElisa reader. Units of TNF activity were defined as the reciprocal of the dilution causing $50 \%$ of maximum cytotoxicity. Human Recombinant TNFa (Biogen BASF/Knoll) with a specific activity of $1.5 \times 10^{7}$ units $/ \mathrm{mg}$ protein was used as internal standard.

Statistical analysis: TNF $\alpha$ activity is reported as units $/ \mathrm{mg}$ protein, $1 \mathrm{mg}$ protein corresponding to $1.7 \pm 0.5 \times 10^{7}$ cells. Evaluation of experimental data was performed using either Mann-Whitney's $U$ test or two-tailed Student's $t$-test with $p \leq 0.05$ as the minimal level of significance.

\section{Results}

Because of the lack of a readily and simply measurable marker of environmental tobacco smoke, $\mathrm{COHb}$ levels were assessed as a reliable indicator of the biological effects of cigarette smoking. Normally in non-smokers, the average of basal COHb levels was $-1 \pm 1.1$ and, as shown in Table 1, COHb levels critically depended on both the number of cigarettes and the time of exposure to cigarette smoke. The decay of $\mathrm{COHb}$ in the blood of the rats was also evaluated after they had smoked three cigarettes for $1 \mathrm{~h}$ and after they were returned to the normal environment. As shown in Fig. 1 the $\mathrm{COHb}$ reached the maximum at the end of the smoking session but in about $2 \mathrm{~h}$ returned to pre-smoking values. The evaluation of the kinetics of alveolar and peritoneal macrophages was carried out in rats that, after undergoing smoking (three cigarettes within a hour), showed a $\mathrm{COHb}$ increase up to $16.4 \%$. Figure 2 (panel A) indicates that the total number of macrophages 


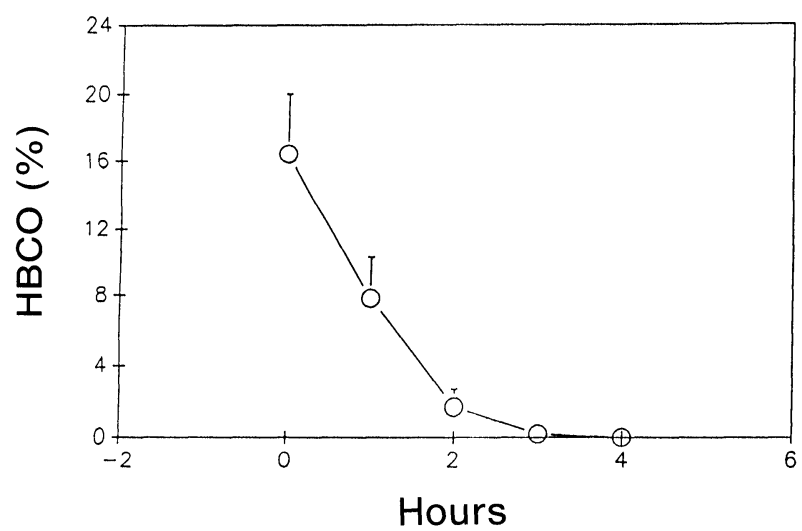

FIG. 1. Kinetics of $\mathrm{COHb}$ in the blood of rats during and after a smoking session (three cigarettes for $1 \mathrm{~h}$ ). Arrows indicate the beginning and the end of the smoking session.

present in the bronchoalveolar lavage significantly increased $8 \mathrm{~h}$ after smoking $(U \leq 0.05)$ in respect to control rats (Fig. 2, panel B). On the other hand the number of peritoneal macrophages remained practically constant in both smokers and controls (Fig. 2, panels $\mathrm{A}$ and $\mathrm{B}$ ). An increase of polymorphonuclear cells (PMN) in the bronchoalveolar lavage was also observed at 8 and $24 \mathrm{~h}$ after an acute smoking episode but it was not statistically significant (data not shown).

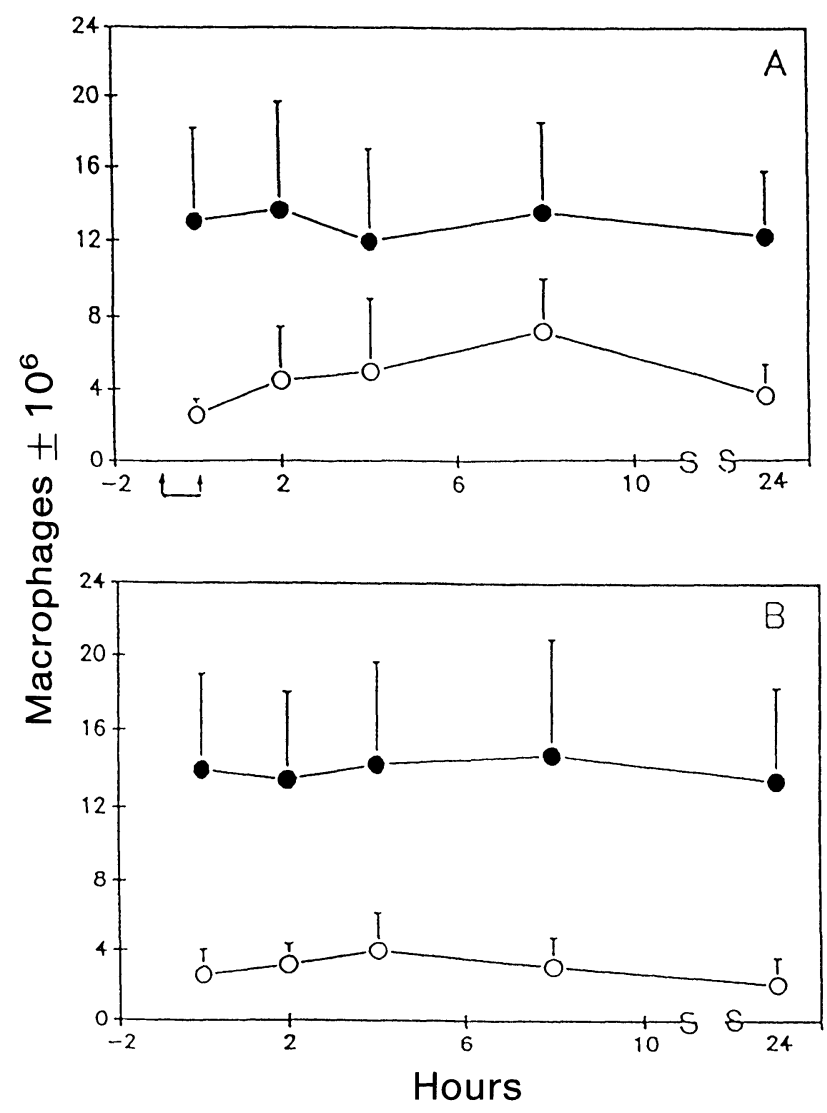

FIG. 2. Kinetics of alveolar $(O)$ and peritoneal $(O)$ macrophages in rats after a smoking session of three cigarettes for $1 \mathrm{~h}$ (panel $A$ ) and in controls (panel B). Arrows indicate the beginning and the end of the smoking session.
Table 2. TNF $\alpha(U / m g$ protein) expressed as mean \pm S.D. released by alveolar macrophages collected various times after the smoking session and incubated for 24,48 and $72 \mathrm{~h}$ at $37^{\circ} \mathrm{C}$

\begin{tabular}{cccc}
\hline & \multicolumn{3}{c}{ Incubation at $37^{\circ} \mathrm{C}(\mathrm{h})$} \\
\cline { 2 - 4 } $\begin{array}{c}\text { Time after } \\
\text { smoking }(\mathrm{h})\end{array}$ & 24 & 48 & 72 \\
\hline 0 & $88 \pm 32$ & $90 \pm 40$ & $76 \pm 31$ \\
4 & $310 \pm 151$ & $283 \pm 184$ & $320 \pm 150$ \\
8 & $525 \pm 210$ & $455 \pm 210$ & $465 \pm 215$ \\
24 & $235 \pm 106$ & - & $250 \pm 150$ \\
Controls & $<10$ & $<10$ & $<10$ \\
\hline
\end{tabular}

The appraisal of the kinetics of alveolar macrophages after acute smoking compelled us to evaluate the eventual activity of these cells by measuring the release of TNF $\alpha$. As shown in Table 2 , alveolar macrophages, collected at various times after acute smoking and incubated for 24, 48 and $72 \mathrm{~h}$ at $37^{\circ} \mathrm{C}$ in a humidified atmosphere, spontaneously released variable amounts of $\mathrm{TNF} \alpha$, which were higher $8 \mathrm{~h}$ after the smoking session. Moreover TNF $\alpha$ production increased up to $24 \mathrm{~h}$ and varied little in the following days of incubation (Table 2). Neither alveolar macrophages of air-sham exposed rats, nor peritoneal macrophages of both control and smoking rats were able to release TNF $\alpha$, which was also absent either in the supernatants of BAL and PL or in plasma. When alveolar macrophages of control and smoking rats, collected 0,8 and $24 \mathrm{~h}$ after the smoking session and incubated for $24 \mathrm{~h}$ at $37^{\circ} \mathrm{C}$, were challenged with LPS, they released much more TNF $\alpha$ (Fig. 3) but, in such a case, the $\mathrm{TNF} \alpha$ release was significantly lower for the smoking group with respect to the control rats.

\section{Discussion}

These studies provide data on the short-term effects of acute cigarette smoking in rats. It is known that cigarette smoking in rabbits and in man causes a

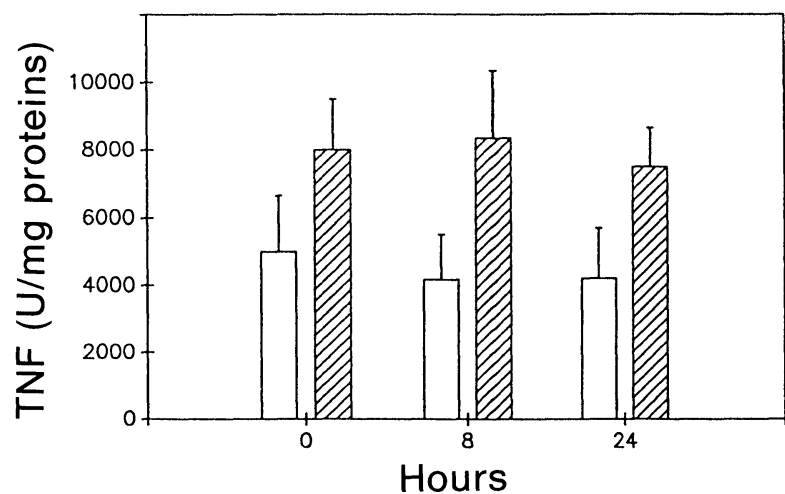

FIG. 3. TNF units/mg proteins expressed as mean \pm S.D. released after induction with LPS by alveolar macrophages collected from smoker (empty columns) and control rats (narrow right diagonal columns) 0,8 and $24 \mathrm{~h}$ after the smoking session. 
rapid increase of $\mathrm{COHb}^{8-13}$ and on this basis a wide range of conditions has been explored yielding a $\mathrm{COHb}$ increase from -1 up to $17 \%$ in rats. $\mathrm{COHb}$ is a reliable marker and the interanimal variability appears small. In the present experimental conditions, reproducibility among different experiments is within $10 \%$. In order to be sure of the acute effect, we selected the protocol of smoke exposure of three cigarettes within an hour for the experiments evaluating the active state of alveolar macrophages. This gave $\mathrm{COHb}$ levels of about $16 \%$, returning to pre-smoke values $2 \mathrm{~h}$ after the smoking session. The evaluation of the kinetic of alveolar macrophages collected from BAL after the smoking session, indicated a significant increase $8 \mathrm{~h}$ after the smoke episode and a little increase of PMN probably due to chemotactic factors ${ }^{14,15}$ At the same time alveolar macrophages, incubated at $37^{\circ} \mathrm{C}$ in a humidified atmosphere, spontaneously released TNF $\alpha$. Although $\mathrm{TNF} \alpha$ release by alveolar macrophages was observed either in rats with silicosis ${ }^{16}$ and mice infected with influenza virus, ${ }^{17}$ or in man as a consequence of Sepsis Syndrome ${ }^{18}$ and Adult Respiratory Distress Syndrome, ${ }^{19}$ our results demonstrated for the first time that alveolar macrophages, collected after an acute smoking episode, were in an active state and spontaneously released TNF $\alpha$. The absence of this cytokine in the BAL could be due to both the dilution and the short time for the cell collection. Additionally, the absence of TNF $\alpha$ in plasma could be explained by both the dilution in body fluids and the rapid clearance of this substance. ${ }^{20,21}$ At a later date the eventual local catabolism of TNF $\alpha$ will be reported. Peritoneal macrophages, representing a resident population remote from the primary site of smoke and perhaps not having direct contact with smoke pollutants and products, were unable to spontaneously release $T N F \alpha$. This clearly indicates that these cells were in a resting state. However, differences in regulation of TNF $\alpha$ production by either human, ${ }^{22}$ or murine ${ }^{23}$ alveolar macrophages stimulated with LPS are well known.

Finally we wanted to ascertain whether a classical inducer such as LPS antagonizes or synergizes with the effect of smoke on alveolar macrophages. It was found that alveolar macrophages collected from control rats released much more $T N F \alpha$ than those collected from smokers, probably because of a negative feed-back and enhanced breakdown due to proteinases released during the incubation period. ${ }^{24}$

\section{References}

1. Anderson R. Assessment of the roles of vitamin C, vitamin $\mathrm{E}$, and $\beta$-carotene in the modulation of oxidant stress mediated by cigarette smoke-activated phagocytes. Am J Clin Nutr 1991; 53: 358S-361S

2. Djordjevic MV, Sigountos CW, Hoffmann D, et al. Assessment of major carcinogens and alkaloids in the tobacco and mainstream smoke of USSR cigarettes. Int J Cancer 1991; 47: 348-351.

3. Robbins RA, Thompson AB, Koyama S, et al. Cigarette smoking and neutrophil migration. I Immunol Res 1990; 2: 178-188.

4. Bonta IL, Ben-Efraim S, Mozes T, Fieren MWJA. Tumor necrosis factor in inflammation: relation to other mediators and to macrophage antitumour defence. Pharmacol Res 1991; 24: 115-129.

5. Bachwich PR, Chensue SW, Larrick JW, Kunkel SW. Tumor necrosis factor stimulates interleukin-1 and prostaglandin $E_{2}$ production in resting macrophages. Biochem Biophys Res Commun 1986; 136: 94-101.

6. Camussi G, Albano E, Tetta C, Bussolino F. The molecular action of tumor necrosis factor- $\alpha$. Eur J Biochem 1991; 202: 3-14.

7. Imaizumi T, Satoh K, Yoshida H, Kawamura Y, Hiramoto M, Takamatsu S. Effect of cigarette smoking on the levels of platelet-activating factor-like lipid(s) in plasma lipoproteins. Atherosclerosis 1991; 87: 47-55.

8. Bosken CH, Doerschuk CM, English D, Hogg JC. Neutrophil kinetics during active cigarette smoking in rabbits. I Appl Physiol 1991; 71: 630-637.

9. Minamisawa $\mathrm{S}$, Komuro E, Niki E. Hemolysis of rabbit erythrocytes induced by cigarette smoke. Life Sci 1990; 47: 2207-2215.

10. Brown GM, Drost E, Donaldson K, MacGregor I, MacNee W. Reduction of the proteolytic activity of neutrophils by exposure to cigarette smoke in vitro. Exp Lung Res 1991; 17: 923-937.

11. Lowry OH, Rosebrough NJ, Farr AL, Randall RJ. Protein measurement with the folin phenol reagent. J Biol Chem 1951; 193: 265-275.

12. Ruff MR, Gifford GE. Tumor necrosis factor. In: Pick E, ed. Lymphokines. New York: Academic Press, 1981; 235-272.

13. MacNee W, Wiggs B, Belzberg AS, Hogg JC. The effect of cigarette smoking on neutrophil kinetics in human lungs. New Engl J Med 1989 ; 321: 924-928,

14. Kunkel SL, Standiford T, Kasahara K, Strieter RM. Interleukin-8 (IL-8): the major neutrophil chemotactic factor in the lung. Exp Lung Res 1991; 17: $17-23$.

15. MacNee W, Selby C. Neutrophil kinetics in the lungs. Clin Sci 1990; 79: 97-107.

16. Mohr C, Gemsa D, Graebner C, et al. Systemic macrophage stimulation in rats with silicosis: enhanced release of tumor necrosis factor- $\alpha$ from alveolar and peritoneal macrophages. Am J Respir Cell Mol Biol 1991; 5: 395-402.

17. Vacheron F, Rudent A, Perin S, Labarre C, Quero AM, Guenounou M. Production of interleukin 1 and tumour necrosis factor activities in bronchoalveolar washings following infection of mice by influenza virus. $J$ Gen Virol 1990; 71: 477-479.

18. Kelley J. Role of cytokines in lung diseases. EOS-J Immunol Immunopharmacol 1991; XI: 140-144.

19. Hyers TM, Tricomi SM, Dettenmeier PA, Fowler AA. Tumor necrosis factor levels in serum and bronchoalveolar lavage fluid of patients with the adult respiratory distress syndrome. Am Rev Respir Dis 1991; 144: 268-271.

20. Bocci V, Pacini A, Pessina GP, Maioli E, Naldini A. Studies on tumor necrosis factor (TNF). I. Pharmacokinetics of Human Recombinant TNF in rabbits and monkeys after intravenous administration. Gen Pharmacol 1987; 18: $343-346$

21. Pessina GP, Pacini A, Bocci V, Maioli E, Naldini A. Studies on tumor necrosis factor (TNF): II. Metabolic fate and distribution of human recombinant TNF. Lympbokine Res 1987; 6: 35-44.

22. Becker S, Devlin RB, Haskill JS. Differential production of tumor necrosis factor, macrophage colony stimulating factor, and interleukin-1 by human alveolar macrophages. J Leuk Biol 1989; 45: 353-361.

23. Stein M, Gordon S. Regulation of tumor necrosis factor (TNF) release by murine peritoneal macrophages: role of cell stimulation and specific phagocytic plasma membrane receptors. Eur J Immunol 1991; 21: 431-437.

24. Ogushi F, Hubbard RC, Vogelmeier C, Fells GA, Crystal RG. Risk factors for emphysema. Cigarette smoking is associated with a reduction in the association rate constant of lung $\alpha 1$-antitrypsin for neutrophil elastase. J Clin Invest 1991; 87: 1060-1065.

ACKNOWLEDGEMENTS. This work was supported by contract no 91.00089 PF41 Targeted Project "Prevention and Control Disease Factors", Subproject 02, CNR-Roma.

Received 29 December 1992; accepted in revised form 18 January 1993 


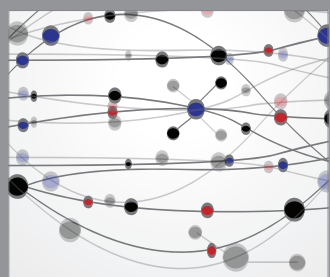

The Scientific World Journal
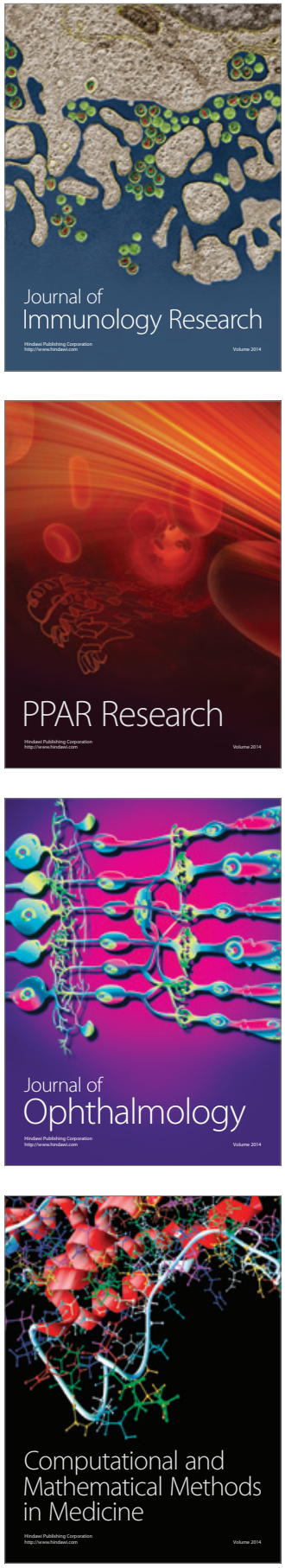

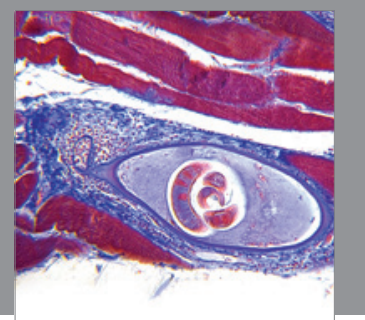

Gastroenterology

Research and Practice
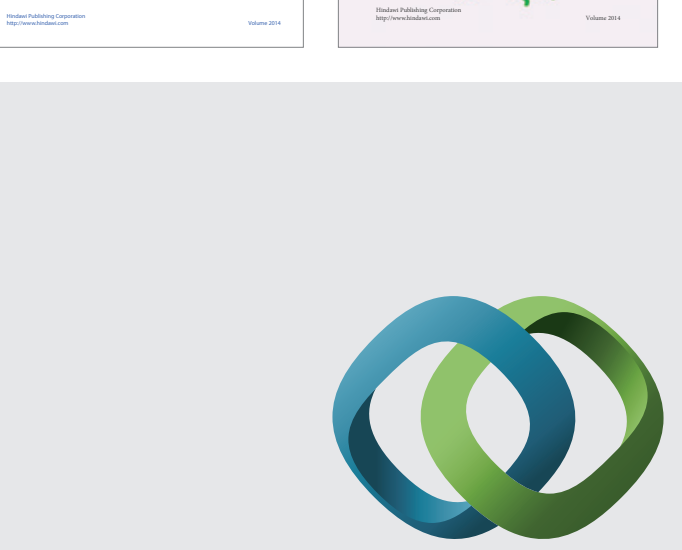

\section{Hindawi}

Submit your manuscripts at

http://www.hindawi.com
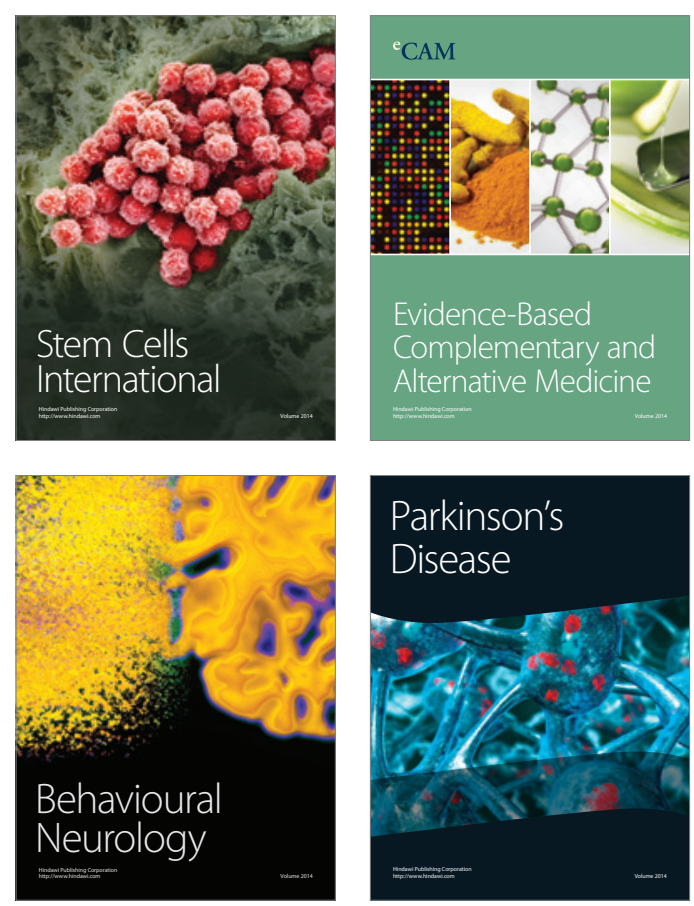

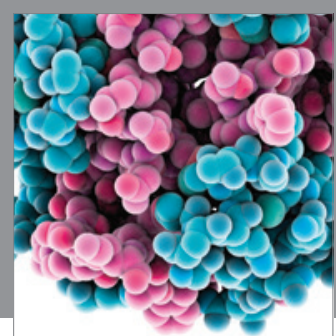

Journal of
Diabetes Research

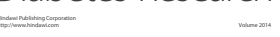

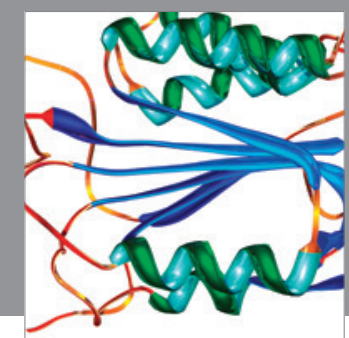

Disease Markers
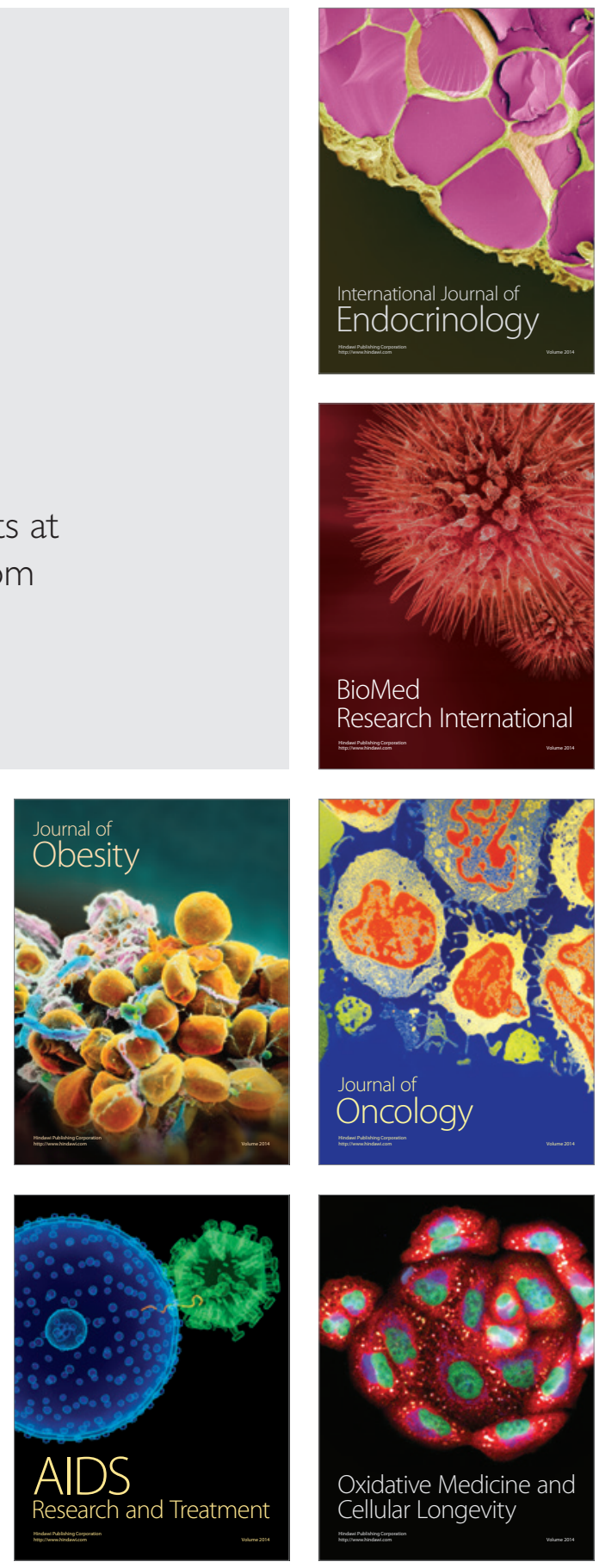